\title{
MUJERES EN LA ESCENA: LA “COMPAÑIIA DE BAILES ESPAÑOLES” DE “LA ARGENTINITA" Y EL ESTRENO DE EL AMOR BRUJO (1933) ${ }^{1}$
}

\author{
Inmaculada Matía Polo ${ }^{2}$
}

\begin{abstract}
Mujeres en la escena: la "Compañía de bailes españoles" de "La Argentinita" y el estreno de El amor brujo (1933)

Resumen: En 1933 Encarnación López Júlvez "La Argentinita", funda su propia compañía de danza, con la que estrenará El amor brujo (1933), primero en el Teatro Falla de Cádiz y después en el Teatro Español de Madrid. Auspiciada por Ignacio Sánchez Mejías y Federico García Lorca, Encarnación logra trasladar a la escena un cambio de paradigma presente en los círculos de intelectuales de la sociedad urbana, con los que se vincula a raíz de su contacto con Gregorio Martínez Sierra y María Lejárraga y sus actuaciones en el Teatro Eslava de Madrid durante la temporada de 1919-1920.

Palabras clave: Danza Española, "La Argentinita”, Martínez Sierra, El amor brujo, Pilar López.

Women in the Scene: the "Company of Spanish Dances" of "La Argentinita" and the Premiere of El amor brujo (1933)

Abstract: Encarnación López Júlvez "Argentinita", founded her own dance company "Compañía de Bailes españoles" in 1933, with which she will premiere El amor brujo (1933), in Teatro Falla (Cádiz) and Teatro Español (Madrid). Supported by Ignacio Sanchez Mejias and Federico García Lorca, Encarnación transfers a paradigm present in the intellectual circles of urban society to the theatrical scene, with which she is linked because of her relation with Gregorio Martinez Sierra and Maria Lejárraga, and her performances at the Teatro Eslava (Madrid) during the 1919-1920 season.

Key words: Spanish Dance, “La Argentinita”, Martínez Sierra, Amor Brujo, Pilar López.
\end{abstract}

\section{Introducción}

La proclamación de la II República el 14 de abril de 1931, significó la plasmación de muchas de las reivindicaciones civiles, jurídicas y políticas relacionadas con el ámbito de la mujer, que activistas como María Zambrano, Constancia de Mora (nieta de Antonio Maura), Carmen de Burgos, la abogada Clara Campoamor, Victoria Kent, o Margarita

\footnotetext{
${ }^{1}$ Fecha de recepción: 21/09/2014.

Fecha de aceptación: 19/10/2014.

${ }^{2}$ Coordinadora de Proyectos de la Biblioteca Nacional de España y Doctora en Historia y Ciencias de la Música; $\triangle$ matiainma@hotmail.com.
} 
Nelken se hacían eco. Se ponían de manifiesto en el ámbito ejecutivo, y posteriormente en el legislativo y judicial, gran parte de las manifestaciones surgidas de la rica efervescencia cultural que recorrió España durante las tres primeras décadas del siglo XX. En este periodo, que se ha venido a llamar Edad de Plata, la intelectualidad sale al encuentro de la cultura relacionada con lo popular y en el ámbito industrial, del mundo obrero $^{3}$. La modernización que goza el país, no puede ser entendida sin la reincorporación de la mujer, sobre todo de la mujer burguesa, al ámbito del trabajo y en los espacios públicos:

[...] dicha incorporación es uno de los signos y síntomas de esa modernidad que buscaba introducir no sólo un nuevo modelo femenino, sino un nuevo modelo de relaciones familiares, e, incluso, yendo todavía mas lejos, un nuevo modelo de sociedad, en la que quedarán definitivamente plasmados los valores de igualdad y de libertad". (Gómez Blesa 2009: 25)

Antecedentes de estos cambios fueron lugares de encuentro como la Asociación para la Enseñanza de la Mujer (1869), la Residencia de Señoritas (1915) derivada del Instituto Internacional (1872), el Lyceum Club Femenino (1926) o determinados ámbitos de la Universidad, donde las mujeres crearon espacios en los que se diseñaba un rol distinto al predominante de madre-mujer abnegada, que se recuperaría (con otros matices) en los años cuarenta. Las feministas vincularon este momento de transformación hacia un nuevo sistema de ordenación del estado, con el cambio efectivo de la situación en la que se encontraba la mujer.

\footnotetext{
${ }^{3}$ Esta constante de populismo campesino, ejemplificado en el propio decreto fundacional de las Misiones Pedagógicas, se entroncaba con el espíritu de la Institución Libre de Enseñanza pero también con el de la tradición estética reciente: desde Azorín de Castilla al Valle-Inclán de las Comedias Bárbaras, desde el Unamuno de Por tierras de Portugal y España al Sorolla de los tipos y pasajes españoles, del Zuloaga de los retablos segovianos a los cuadros de los recientes pintores de la Escuela de Vallecas. Era evidente que la imagen plástica y moral del país se continuaba relacionando con la España de campo abierto, dejando de lado el incremento de la población urbana e incluso del protagonismo ciudadano de la República (Mainer 2006: 80)
} 


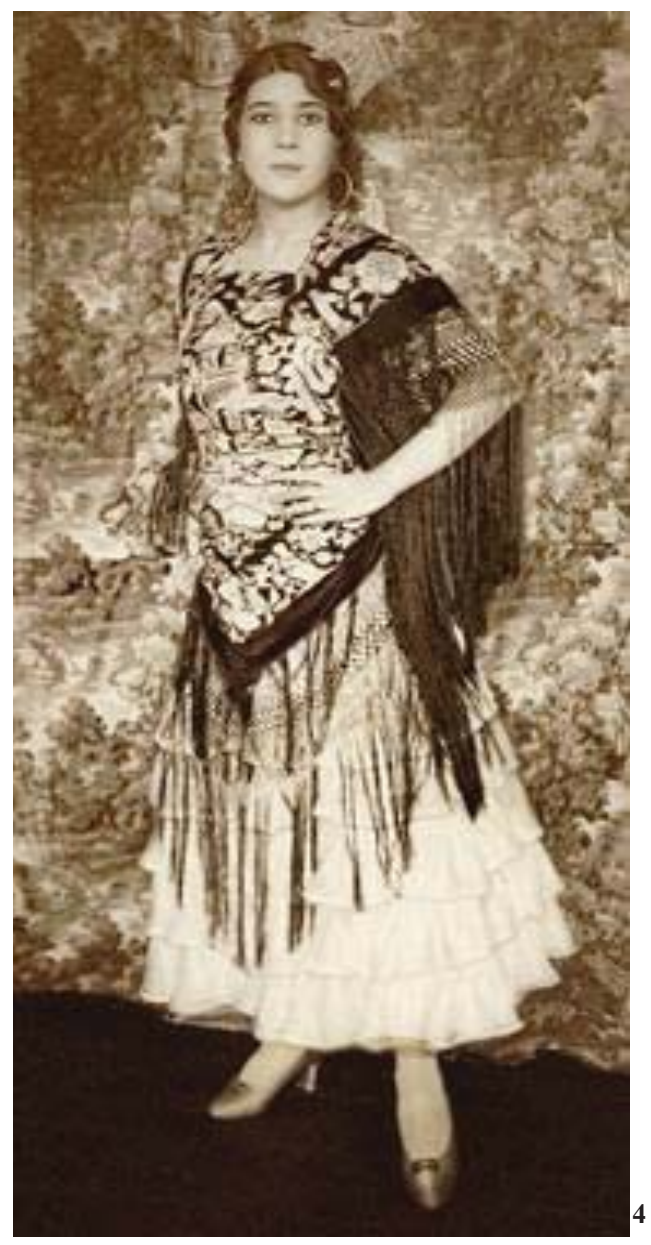

En el campo de las ideas, la filosofía metafísica de Karl Christian Friedrich Krause (1781-1832), que penetra en España a través de Julián Sanz del Río (1814-1969) y Francisco Giner de los Ríos (1839-1915), contribuyó a la creación de un nuevo estatus vinculado a lo femenino. Este pensamiento derivado del racionalismo alemán encabezado por Hegel, se asienta y condiciona el proyecto pedagógico de la Institución Libre de Enseñanza (ILE). En él se afirma la supremacía e independencia del hombre en todos los ámbitos de su desarrollo, ejercitada a través de la de la razón y del libre examen, desmarcándose de esta manera de las corrientes más conservadoras del pensamiento católico español (Fernández de la Cuesta, en Sánchez de Andrés 2009: 7). Se priorizan aspectos relacionados con la educación y la cultura, el valor del conocimiento, las artes,

\footnotetext{
${ }^{4}$ Figura 1 "La Argentinita”, ca. 1925. (Del Cuplé a la Revista: 2013)
} 
la naturaleza y en el ámbito normativo, el desarrollo de los derechos de la infancia y de la mujer

Este cambio de paradigma, presente en los círculos de intelectuales de la sociedad urbana, se traslada al ámbito del teatro. De acuerdo con un espíritu eticista (que se desmarca del moralismo cristiano) se rechazan géneros como los del cuplé o de la canción ligera, así como creaciones que no contribuyan a la evolución de la sociedad a través de un compromiso moral, pedagógico y social. El artista adquiere un compromiso ético con la comunidad por la importancia de su labor. Un compositor no debe producir obras groseras que exhibidas perviertan el gusto natural del público, sino aquellas que cumplan las leyes de la belleza ideal y que eleven al arte musical, y con él a la Humanidad, a un estadio superior. Por otra parte, el público no es sólo un receptor pasivo, sino que también puede colaborar en este progreso, ya que su gusto musical (educado a través de la crítica, las asociaciones con afán instructivo musical y textos científicos de vulgarización o divulgación) le permitirá seleccionar las obras de calidad (Sánchez de Andrés 2009: 83).

El rechazo a estos géneros del teatro, se relaciona con un intento de la equiparación cultural de la mujer con el hombre, a través de la formación (educación superior) y la adquisición de responsabilidades en el ámbito del trabajo (frente al estatuto "histórico" de la mujer española, cuya identidad oscilaba entre objeto-estético, instrumento de placer masculino o esposa-madre, sin la posibilidad de acceder nunca a la madurez social y profesional). No era fácil, ya que en el espacio de la canción-espectáculo las varietés tenían asociadas una tradición secular del papel de la mujer, tanto en sus perspectivas artísticas (el estatuto de vedette), como en sus facetas "consumistas" (pornografía y "voyeurismo) (Salaün 1990: 80). Esto propició tanto un concepto determinado de lo que ocurría en la escena, es decir, lo que el espectador esperaba ver, así como el establecimiento de roles (mujer- intérprete- hombre- empresario), el desarrollo de usos sociales y una legislación pensada para ese tipo de espectáculos (Ramos 2003: 91).

Estas tesis de cambio, presentes en ámbitos institucionistas, se relacionan íntimamente con los presupuestos feministas y sufragistas, en los que se abogaba por una mujer que si bien tenía que generar sus propios medios de subsistencia para conseguir la 
libertad: "La mujer que no trabaja, se corrompe, y de compañera del hombre se convierte en esclava del hombre" (Martínez Sierra 2003: 47), había de acompañar esta tarea con una formación adecuada que les permitiese trascender su posición subordinada $\mathrm{y}$ descubrir su propia vocación (Martínez Sierra 1931). El dramaturgo, escritor y empresario Gregorio Martínez Sierra aboga por la creación de cooperativas de producción femeninas, donde el hombre quedase al margen de los procesos empresariales y fuera la mujer la encargada no sólo de llevar a cabo la manufactura, sino hacerse cargo de la toma de decisiones (Gómez Blesa 2009: 95). Asimismo, María Lejárraga, en apoyo al gobierno republicano, señala en un ciclo de conferencias leídas en el Ateneo de Madrid en mayo de 1931, que llevan por título La mujer española ante la República:

Mujeres ambiciosas, el Gobierno de la Buena Voluntad Española os puede dar puestos y responsabilidad. Mujeres generosas, el Gobierno de la República os puede dar deberes, Mujeres justas, La República os puede dar derechos. ¡Puede, sabe, quiere y le conviene! ¡Juntemos conveniencias para salvar a España! (Martínez Sierra, en Gómez Blesa 2009: 227)

\section{La "Compañía de Bailes Españoles" de "La Argentinita"}

Es en este contexto reformista cuando en el ámbito de la danza española primero Antonia Mercé "La Argentina” (1888-1936) en 1928, y posteriormente Encarnación López Júlvez "La Argentinita" (1897-1945), en 1933, deciden emprender su propia aventura empresarial como directoras de Compañía de Danza. Ambas relacionadas con la vanguardia, es primero "La Argentina", también en contacto con Lorca, Cipriano Rivas Cheriff $^{5}$, el pianista Joaquin Nin (padre de la la escritora Anaïs Nin) o Adolfo Salazar,

\footnotetext{
${ }^{5}$ Uno de los protagonistas del Teatro en este ambiente reformador del primer cuarto de siglo, fue Cipriano Rivas Cherif, a través de su impulso en la renovación de los autores, las obras y la puesta en escena de los grupos con los que trabajó. Gran parte de su etapa formativa transcurrió fuera de España, y este factor le puso en contacto con las ideas desarrolladas por figuras como Craig, Jacques Copeau y Max Reinhardt. Su actividad aparece relacionada tanto en la elaboración de pequeños teatros de arte, como en la creación de
} 
quien presenta a la prensa en la Ópera Comique de Paris los Ballets Espagnols de L'Árgentina, nombre que después cambiaría por el de Argentina y sus Ballets Espagnols (Marinero 1999: 662). El nombre en francés remitía a los Ballets Russes de Diaghilev, pero el apellido recordaba su filiación española. A través de esta formación en la que “[...] se había responsabilizado por contrato de los salarios de una amplia compañía de bailarines, músicos y colaboradores escénicos, con los que hacía giras por todo el mundo [...]" (Devorah Bennahum 2009: 143), "La Argentina” crearía más de diez nuevos ballets hasta 1936, año en el que fallece. Aunque en 1927 "La Argentinita" aparece vinculada a la fundación de la Compañía de Baile Andaluz en relación con el estreno de La romería de los cornudos (Pittaluga) ${ }^{6}$, su participación no adquiere la perdurabilidad y el significado de la Compañía de Bailes Españoles, con el que el 10 de junio de 1933 estrena El amor brujo en el Teatro Falla de Cádiz. En bibliografía secundaria se le ha relacionado con la dirección de "El Ballet de Madrid" en 1932, pero de un vaciado de prensa y programas de mano no he encontrado ninguna información que confirme este aspecto ${ }^{7}$.

Para entender el paso de "La Argentinita" de estrella de las variedades a musa de la vanguardia, introduciré unas breves líneas biográficas que nos ayuden a establecer la relación entre estos dos aspectos. Nacida en 1897 en Buenos Aires, "La Argentinita" pronto se trasladó a España, donde empezó a triunfar en el ámbito de las variedades, primero en San Sebastián y ya en Madrid, con sus actuaciones en el Teatro Romea. Aunque al igual que el resto de bailarinas, apenas había recibido estudios generales mas allá de la que le proporcionaban los escenarios, Encarnación compagina sus actuaciones en los teatros con colaboraciones con los intelectuales de la Edad de Plata que encontraron

\footnotetext{
obras de danza en colaboración con Antonia Mercé "La Argentina", Encarnación López "La Argentinita" y otros intelectuales y artistas del teatro de la II República. Su figura es, por tanto, una significativa bisagra en el aparato teatral que se desarrolla en esta época (Murga de Castro 2009: 83).

${ }^{6}$ Escrita por Gustavo Pittaluga para Antonia Mercé "La Argentina", con esta obra Encarnación se inicia en la coreografía de ballets en gran formato. (Casares 2000: 834)

${ }^{7}$ En los programas de la época aparece referida simplemente como "Argentinita", con un repertorio compuesto tanto por piezas del segundo nacionalismo español y del Grupo de los ocho, como por las canciones populares, recogidas y armonizadas por Federico García Lorca, que había grabado en 1931 para el sello discográfico $L a v o z$ de su amo, y que eran el principal reclamo. El rotativo $A B C$, aunque no menciona El Ballet de Madrid, refiere que en 1932 "La Argentinita", aconsejada por Sánchez Mejías y Edgar Neville forma su compañía de danza, presentándose con las estampas folclóricas Las calles de Cádiz, Sevillanas del siglo XVIII, El café de Chinitas y El tango del escribano. (Marinero 1999: 662; ABC, 1996: 101)
} 
en ella, pero también en bailarinas como Pastora Imperio o "La Argentina", figuras de la escena que les permitirían trasladar sus reflexiones en cuanto a la búsqueda de una estética dancística determinada - danza española-. En este sentido, participó en la ilustración de conferencias ilustradas, una de las cuales "Elogio de la danza" estuvo a cargo de Gregorio Martínez Sierra ${ }^{8}$, así como en el ámbito cinematográfico, en la grabación de películas como Flor de Otoño (Mario Caserini 1916) o Rosario la Cortijera (José Buchs 1923). En la temporada de 1919-1920, comienza a formarse en el campo de la interpretación y se vincula a la Compañía de Martínez Sierra, colaborando en diferentes producciones que tuvieron lugar en el Teatro Eslava de Madrid, activo entre septiembre de 1916 y enero de 1926.

Junto con Rosaura la viuda astuta (1920), La suerte de Isabelita (1920) y Kursaal (1920), el 22 de marzo de 1920 estrena El maleficio de la mariposa, con texto de un joven Federico García Lorca ${ }^{9}$. Para esta representación “La Argentinita” interpretó el papel de "Mariposa Blanca", por lo que Lorca atribuyó los textos que en un principio le pertenecían a la Mariposa, al otro protagonista principal de la trama, Curianito, dejando al personaje únicamente con la expresión movimientos (Meranini 1999: 33) La escenografía contó con decorados de Mignoni y figurines de Rafael Barradas (Murga de Castro 2009: 84). Es a partir de este estreno cuando "La Argentinita" incrementa su contacto con el círculo de intelectuales que se concentraban en torno a la Residencia de Estudiantes y, en este contexto, destaca las colaboraciones llevadas a cabo con Ignacio Sánchez Mejías (Jiménez Chávarri), con el que establecerá una relación sentimental durante más de una década. Su participación en la Residencia no sólo se vincula a la relación estrecha que tuvo con García Lorca, Pittaluga, o Rosita Ascot, sino que en ese espacio acompañó la lectura de conferencias, colaboró con el grupo de teatro universitario "La Barraca",

\footnotetext{
${ }^{8}$ En esta conferencia participaría asimismo el bailarín belga Felyne Verbist, que interpretó la Ninfa de Diana de Delibes, la Muerte del cisne de de Saint Saëns y la Visión de Salomé de Joyce (La Correspondencia de España.1915: 5)

${ }^{9}$ Para Lorca se trataba de su primera incursión escénica. A petición de Martínez Sierra y su amante por entonces, la actriz Catalina Bárcenas, adaptó un texto escrito inicialmente para un teatro de guiñol en un libreto de teatro, lo que fue achacado por la crítica como parte de su fracaso.
} 
dirigido por Federico García Lorca y Eduardo Ugarte en su primera etapa (1932-1936) ${ }^{10}$ y presentó a su compañía el 15 de junio de 1933 (Morla Lynch 1957: 355).

Impulsada por este ambiente reformista, en 1932 con la ayuda del propio Lorca y Sánchez Mejías, comienza los preparativos para crear su propia formación de danza, para la que incorpora a su hermana Pilar. Con ella, estrenará El amor brujo, quizás el más icónico de sus ballets el 10 de junio en el Teatro Falla de Cádiz. Tres días después lo hará en el Teatro Español de Madrid.

A pesar de su éxito entre el público y la prensa de entonces, y su vinculación con las figuras representativas de la Edad de Plata, Adolfo Salazar le achaca no haber sabido establecer las danzas populares como medio para la creación de un estadio cultural superior, como sí hizo sin embargo Antonia Mercé "La Argentina”:

[...] Cuando "La Argentinita" intentó llevar la danza popular de varias regiones a los teatros españoles o neoyorquinos, solamente logró una especie, fina y atractiva, de varietés, pero no otra cosa. Menos, naturalmente, sus imitadores [...] (Salazar 1956: 232)

La crítica posterior incide en esta argumentación señalando el fracaso de la Argentinita por superar la frontera de lo regional y elaborar un producto artístico que trascendiera lo popular, para elevarlo al espacio europeo a través de la cultura, entendida esta como elaboración y creación (Martínez del Fresno 2009: 459). Sin embargo, y coincido en este aspecto con la profesora Segarra, distanciándose de los ballets narrativos de "La Argentina", Encarnación no trató de crear un nuevo lenguaje español, sino que focalizó su interés en una danza vinculada al folklore, con una construcción del material popular en la línea de García Lorca (Segarra 2012: 58). En su proceso coreográfico, y posteriormente en el de su hermana Pilar, estaba presente la reflexión hacia una estética

\footnotetext{
${ }^{10}$ Para ellos montó unas sevillanas que se insertaría en la obra El retablo de las maravillas, así como inspiró puestas en escena capturó poses y colocaciones en la obra, que constatan un claro sentido coreográfico, tanto en los gestos individuales como en el movimiento de grupo.
} 
minimalista, sin pretender la vanguardia o la ruptura de cánones estilísticos, sino más bien la simplificación de los mismos (Álvarez Caballero 1997: 95). No obstante, en este sentido, todavía es preciso un estudio coreológico, especialmente de creaciones como $E l$ amor brujo, que la crítica de Estados Unidos remarcó su éxito, por encima de las versiones de Argentina y Vicente Escudero, La vida breve y sobre todo el Bolero de Ravel (Biancolli 1945).

Para estas primeras representaciones, "La Argentinita" cuenta con la presencia de su hermana Pilar López (como segunda figura de la Compañía. Si bien habían compartido hasta entonces en ocasiones escenario, a partir de ese momento sus carreras se vincularán de manera definitiva.

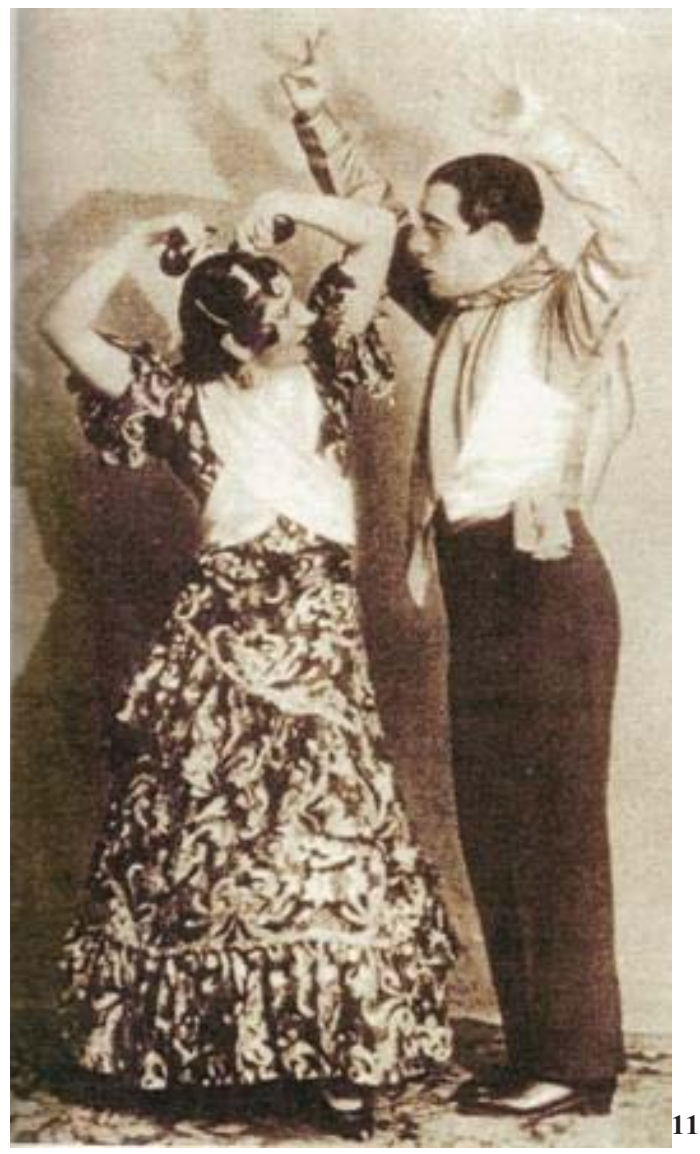

\footnotetext{
${ }^{11}$ Figura 2. Pilar López con Rafael Ortega. Ca. 1940. (Bohórquez: 2012)
} 
Además de Pilar, completan el elenco de la escena Rafael Ortega, que en El amor brujo, ejecuta el papel de "El Espectro"; Antonio Triana, en el rol de "Carmelo" y las gitanas conocidas como "La Macarrona", "La Malena" y "La Fernanda" como "Hechiceras" (Diario de Cádiz 1933). El diplomático Carlos Morla Lynch, amigo personal de Lorca y muy vinculado a la Residencia, retrata la singularidad de estas tres mujeres, por entonces cada una de ellas con más de setenta años y como, a través de su presencia, consiguen trasladar al espectador a un imaginario relacionado con el ambiente de los antiguos cafés-cantante y a la vez con aspectos mágicos y ancestrales:

[...] Sin duda que el clou del espectáculo lo constituye la aparición sensacional en la escena -con gran repiqueteo de castañuelas- de las tres viejas "bailaoras" que son acogidas con una ovación delirante. Con sus cuerpos torcidos, sus rostros arrugados - severos y llenos de dignidad-, sus oscuras mantillas de encaje y sus trajes morados de muchos vuelos y de colas muy largas, levantan los brazos, ondulan y mueven las manos, con una gracia y un donaire que nunca podrá ser igualado. Salero incomparable de ancianas que fueron en su tiempo "castigadoras y guapas". Caprichos de Goya que adquirieron vida en una noche de magia. "El triunfo de la fealdad: la belleza insuperable de lo horrible"- dice Rafael Rodríguez Rapún.- Y no podría haber definición más elocuente y gráfica. Infunden una emoción jamás sentida antes, más alla de lo humano... (Morla Lynch 1957: 354)

La dirección musical estuvo a cargo de Ernesto Halffter, tanto en la representación de Cádiz como de Madrid, que dirigía La Orquesta Bética de Cámara ${ }^{12}$. La primera parte contaba con música íntegramente de Manuel Falla, interpretándose la suite de El sombrero de tres picos, y El amor brujo, que suponía la principal expectación y el reclamo de estreno ${ }^{13}$. En la segunda, se intercalaron distintas danzas de corte popular, habituales del repertorio de "La Argentinita", como fueron Sevillanas del siglo XVIII,

\footnotetext{
12 Esta formación compuesta por Falla que “...se dedicó a buscar los músicos que le interesaban por los más apartados rincones andaluces...", era la primera agrupación que interpretaba la música autoría de su fundador [...]" (Seray y Casas 1933)

${ }^{13}$ En la memoria colectiva estaban presentes las versiones de El amor brujo que hicieron primero de Pastora Imperio en 1915 y posteriormente Antonia Mercé y Vicente Escudero en 1925.
} 
Los cuatro muleros (García Lorca), Jota de Alcañiz (Font), Negritos y Aires de Cádiz (Popular), Aires de Castilla (Gombau), Triana de (Albéniz) y las piezas Andaluza, La danza de la Molinera y la "Farruca" de El sombrero de tres picos, estas tres últimas también autoría de Falla (Programa El amor Brujo, Teatro Español, 1933). La tipología de repertorio escogido claramente destilaba una vocación por lo popular, lo que aseguraba que el público encontraría referentes auditivos que le hicieran conectar rápidamente con la escena ${ }^{14}$.

La crítica a estas representaciones tanto en Andalucía como en Madrid, y a la nueva formación de "La Argentinita", resaltó unánimemente su éxito en el público. A modo de ejemplo, rotativos como El Diario de Cádiz, que hacía hincapié en la heterogeneidad del grupo, o El Sol, que incidía en el españolismo de la agrupación, señalaron el día después del estreno:

[...] Citar nombres para hacer resaltar la labor individual sería inducir al lector a la creencia de posibles desigualdades, y precisamente el espectador da la sensación de una perfección de conjunto inusitada. Ni en los intérpretes, ni en los sucesivos números de la obra podríamos anotar cosa mejor o peor a otra: todos y en cada momento dan la sensación de lo sencillamente perfecto [...] (Diario de Cádiz, 1933)

[...] Hay que decir en seguida que el españolismo más neto, el de más recia fibra, el de más amarga raíz, más áspera y más dura, es el españolismo que ayer se vio en el espectáculo de danzas organizado por la Argentinita. Tanto en el El amor brujo, como en la espléndida sucesión de danzas sueltas que siguieron en la segunda parte del programa y que terminaron con algo tremendo: las "Alegrías" de las tres viejas maestras de la danza. La Macarrona, la Malena, la Fernanda a las que se añadió Rafael Ortega[...] (El Sol 1933)

\footnotetext{
${ }^{14}$ A través de la utilización de de un corpus folklórico, para una finalidad no folklórica, es decir, la utilización de unas modalidades expresivas fuera de su función original, fuera de su contexto socio-cultural (Salaün 1990: 17)
} 
Tras estas actuaciones, que se completaron con la presentación de El amor brujo el día 15 de junio en la Residencia de Estudiantes, Encarnación inició una gira por escenarios de España, incluyendo en su recorrido durante el año 1933 el Teatro Principal (Valencia), el Teatro Rosalía de Castro (Vigo), el Teatro Calderón (Valladolid), o el Teatro Arriaga (Bilbao).

La muerte inesperada de Ignacio Sánchez Mejías 13 de agosto de 1934, el día de su reincorporación a los ruedos, deja sumida a Encarnación en una profunda tristeza, que le decide a salir de España. Ese mismo mes es contratada por el Teatro Colón de Buenos Aires y, aunque vuelve puntualmente a la península, permanece a partir de entonces casi en constante gira por Hispanoamérica, donde ya era una artista consagrada.

Impulsada por el empresario Sol Hurok, en la década de 1940 Encarnación fija su residencia en Nueva York. Con la ayuda de su hermana Pilar, es en esta ciudad en la que estrenaría algunas de sus más importantes coreografías: El bolero, de Maurice Ravel, en la sala Carnegie Hall (1942) y El café de Chinitas, en el Metropolitan Opera House (1943). En la Fundación Argentinita-Pilar López, se conservan las fotografías y la escenografía que lo representan. La enfermedad de Encarnación a principios de 1945 le obliga a ser ingresada en el Presbiterian Hospital Medical Center de Nueva York, lugar en el que fallece el 24 de septiembre de 1945.

\section{Conclusiones}

A pesar de los intentos educacionales tanto de la intelectualidad como del Gobierno de la República, no fueron capaces a corto plazo de modificar los gustos adquiridos por el público, es decir el predominio de la llamada "subcultura" -entendida como espectáculos teatrales de carácter frívolo (Mainer 1983: 283). El principal reclamo seguían siendo los números de variedades, donde el espectador no iba buscando tanto la calidad estética de la interpretación, sino piezas breves que llevasen aparejado la 
comicidad, lo extravagante o en el caso de las mujeres la sensualidad, lo fatuo y lo accesible.

En los años cuarenta, con el fin de la contienda y la instauración del régimen franquista, la imagen femenina propuesta por el franquismo vuelve a situarse al margen de la esfera pública. Frente a anteriores movimientos reformistas, desde la oficialidad de las instituciones se buscará una mujer al amparo de la figura masculina y los poderes que la sociedad establece. Será la época dorada de la Revista, representada en vedettes como Celia Gámez, Queta Claver o Virginia de Matos. La danza española, con la muerte de "La Argentina" en 1936, el exilio de "La Argentinita" y su fallecimiento en 1945 y los contratos por América de Carmen Amaya y Antonio y Rosario, después "Antonio, el bailarín", queda en un auténtico estado de orfandad. Tendremos que esperar a la segunda mitad de la década de los cuarenta para que se produzca el retorno a España, primero de Pilar López en 1946, responsable del legado artístico de "La Argentinita", para presentar su "Ballet Español" en el Teatro Fontalba de Madrid ${ }^{15}$ y, tres años después, en enero de 1949 de "Antonio y Rosario" que debutarán también el Fontalba con el nombre de "Los Chavalillos Sevillanos".

\section{Referencias Bibliográficas}

Programa de mano "El amor brujo". 13 de junio 1933. Teatro Español. Madrid: Fundación Argentinita - Pilar López.

Programa de mano "Los Ballets Españoles de Pilar López". 6 de junio de 1946. Teatro Fontalba. Madrid: Fundación Argentinita - Pilar López.

"La Fiesta de la danza". 18 de abril de 1915. La Correspondencia de España: 5.

\footnotetext{
${ }^{15}$ La permisividad del régimen con esta formación, que en su programa llevaba los nombres de Alberti y Federico, se justifica por aspectos como la recuperación del folclore -entendido como búsqueda de una identidad nacional-, autenticidad y respeto a la tradición. Además, su presencia servía para unir simbólicamente a una España políticamente dividida, e internacionalmente proyectaba la imagen de un régimen que valorizaba una cultura, una alta cultura que reafirmaba la idea superior de España (Casero, 2000: 77).
} 
“El amor brujo". Diario de Cádiz, s/f (1933). Fundación Argentinita - Pilar López.

“El amor brujo en el Español”. El Sol s/f (1933). Fundación Argentinita - Pilar López.

$A B C .11$ de junio de 1996. Madrid: 101.

Del Cuplé a la Revista. 25 de enero, 2013: http://delcuplealarevista.blogspot.com.es/2013/01/un-mito-llamado-imperio-primeraparte.html [4 de abril, 2014].

Álvarez Caballero, Ángel. 1997. Pilar López: una vida para el baile. La Unión: Concejalía de Cultura.

Biancolli, Louis. 9 de abril, 1945. "The Dance, New York World Telegram.

Bohórquez, Manuel. 30 de mayo, 2012. La Gazapera, El Correo de Andalucía. http://blogs.elcorreoweb.es/lagazapera/2012/05/30/rafael-ortega-carlota-ortega-y-enriqueel-almendro-eran-biznietos-de-antonio-monge-el-planeta/. [14 de abril, 2014].

Casares Rodicio, Emilio, 2000. "Pittaluga, González del Capillo, Gustavo". Diccionario de la Música Española e Hispanoamericana, vol. 8. Ed. Emilio Casares Rodicio. Madrid: SGAE. 834.

Casero García, Estrella, 2000. La España que bailó con Franco. Madrid: Editorial Nuevas Estructuras.

Devorah Bennahum, Ninotchka. 2009. Antonia Mercé: El flamenco y la vanguardia española. Barcelona: Global Rhythm Press.

Gómez Blesa, Mercedes. 2009. Modernas y vanguardistas: Mujer y democracia en la II República. Madrid: Ediciones de Laberinto S.L.

Mainer, José Carlos. 1983. La Edad de Plata (1902-1939). Madrid. Cátedra. . 2006. Años de vísperas: La vida de la cultura en España (1931-1936). Madrid: Espasa.

Marinero, Cristina. 1999. "Argentina, La (Antonia Mercé Luque)". Diccionario de la Música Española e Hispanoamericana, vol. I. Ed. Emilio Casares. Madrid: SGAE. 662-664.

Martínez del Fresno, Beatriz. 2009. "Los lenguajes musicales de la Edad de Plata: modernidad, elitismo y popularismo en torno a 1927". Música y cultura en la Edad de Plata 1915-1939. Madrid: Colección Música Hispana ICCMU. 455-478.

Martínez Sierra, María.1931. La mujer española ante la República. Madrid: Ediciones de la Esfinge.

2003. "Antología de textos". A las mujeres: ensayos feministas de María Martínez Sierra. Ed. Alda Blanco. Logroño: Gobierno de la Rioja - Instituto de Estudios Riojanos.

Meranini, Piero. 1999. "Prólogo”. El maleficio de la mariposa. Madrid: Cátedra. 33.

Morla Lynch, Carlos. 1957. En España con Federico García Lorca. Madrid: Renacimiento. 
Murga de Castro, Idoia. 2009. Escenografia de la danza en la Edad de Plata (1916-1936). Consejo Superior de Investigaciones Científicas: Madrid.

Ramos, Pilar. 2003. Feminismo y música. Madrid: Narcea.

Salaün, Serge. 1990. El cuplé (1900-1936). Austral: Madrid.

Salazar, Adolfo. 1956. La danza y el ballet. México: Fondo de Cultura Económica.

Sánchez de Andres, Leticia. 2009. Música para un ideal: Pensamiento y actividad del krausismo e institucionismo españoles (1854-1936). Madrid. SEDEM.

Segarra Muñoz, María Dolores. 2012. Antonio Ruiz Soler y la Danza Estilizada: Configuración $y$ desarrollo de un género. Tesis Doctoral, dir. Javier Suárez Pajares. Madrid: Universidad Complutense de Madrid.

Seray y Casas, T. 1933. "Redescubrimiento de Andalucía". La voz de Aragón. Zaragoza. Archivo de la Fundación Argentinita - Pilar López. 